\title{
Applying the dimensional method for valuation of the strength loss of cement compositions exposed to elevated temperatures
}

\author{
Nikita Levashov ${ }^{1}$, Marina Akulova ${ }^{2}$, Olga Potemkina $^{3}$, Alla Sokolova $^{4 *}$ and Yulia Sokolova ${ }^{5}$ \\ ${ }^{1}$ Military unit 65451, the Ministry for Defence of the Russian Federation, 153000, Ivanovo, Baturina \\ street, 12, Russia \\ ${ }^{2}$ Ivanovo State Polytechnic University, the Department of buildings materials science, special pro- \\ cesses and technological complexes, 153000, Ivanovo, Sheremetevskij prospekt, 21, Russia \\ ${ }^{3}$ Academy of the State Firefighting Service, Ministry of Emergencies in Russia, Department of Aca- \\ demic Work, 153040, Ivanovo, prospekt Stroitelei, 33, Russia \\ ${ }^{4}$ Moscow State University of Civil Engineering, Yaroslavskoe shosse, 26, Moscow, 129337, Russia \\ ${ }^{5}$ Research Institute of Building Physics of the Russian Academy of architecture and building sciences, \\ 127238, Moscow, Lokomotivniy proezd, 21, Russia
}

\begin{abstract}
The paper presents the basis of the analytical model for calculating the loss of strength in ce-ment compositions exposed to elevated temperatures. This model is to replace the classical method of calculating the fire resistance of the loss of load-bearing capacity. The experimental data were taken as initial indicators. Based on the implemented calculations it would become possible to predict the occurrence of ultimate state by loss strength and the reliability of practical indicators obtained by means of full-scale tests
\end{abstract}

\section{Introduction}

Nowadays, with the purpose of true study of non-combustible building materials behavior at elevated temperatures near to a standard case of fire [1], the new innovative approaches to the processes taking place in the researched building structural materials are being developed actively. According to the obtained results of the research, it becomes possible to predict the behavior of building structural elements on the base of cement compositions. Now, this possibility is given by such research methods as fire resistance test of building structures, thermal analysis of inorganic compounds, X-ray diffraction technique and others.

The analysis of applied methods [2-6] proves that the existing approaches to evaluation of fire- and thermal stress resistance of stone building materials take into the account only particular properties and therefore are not accurate and complete. The studied analytical methods of manifestation of properties by newly engineered materials on the base of cement compositions exposed to elevated temperatures do not comprise the complex criterion based on integration of thermal-physical, thermal-chemical and physical-mechanical properties obtained by laboratory testing as well as by analytical calculation of evaluation of ultimate limit state point (criteria R, I - structural failure, thermal insulating capacity loss). 
None of the existing methods for evaluation and analysis of behavior of building materials on the base of cement compositions at elevated temperatures consider the current issue in the context of the complex of measures with theoretical and practical feasibility demonstration.

Thus, a need arises for development of the complex approach to analysis of materials' behavior at elevated temperatures in building structures in order to evaluate contribution of building material to the propagation of fire and fire resistance of building structures.

Urgency of the present method development is based on the fact that its application would give the possibility to evaluate probability, type and rate of warming-up as well as the strength loss of building materials.

\section{Materials and methods}

In the present paper, the authors propose application of the dimensional method as a key instrument for mathematical valuation of behavior of building materials on the base of cement compositions at elevated temperatures.

Upon the earlier developed approach to the evaluation of behavior of cement compositions of building structures $[7,8,9]$, the work aimed at the search and integration of existing mathematical models for complex behavioral analysis of cement compositions of building structures at elevated temperatures was carried out. The dimensional method had been taken as an underlying theory for mathematical evaluation of ultimate limit state point in the case of fire by strength loss $(\mathrm{R})$.

\section{Results}

The key criteria in the mechanism of the material's strength loss are factored in the present analytical model.

According to the dimensional method, in the functional relationship of strength loss the values not related functionally are factored in:

$$
\Delta \sigma=f(l, a, t, \vartheta, k)
$$

where: $l-$ specimen length;

$a-$ temperature diffusivity coefficient of material;

$t-$ process time;

$\vartheta$ - furnace temperature;

$k$-dimensional Boltzmann coefficient.

In the system of the principal dimensions: $\mathrm{M}$ - mass, $\mathrm{L}$ - length, $\mathrm{T}$ - time, $\mathrm{Q}$ - temperature, the values included in the formula (1) are presented in the Table 1.

Table 1. The principal dimensions of values applied in the analytical model of evaluation of ultimate limit state point following the strength loss

\begin{tabular}{|l|c|c|c|c|c|c|}
\hline Value & $\Delta \sigma$ & $l$ & $a$ & $t$ & $\vartheta$ & $k$ \\
\hline Dimension & $M L^{-1} T^{-2}$ & $\mathrm{~L}$ & $L^{2} T^{-1}$ & $\mathrm{~T}$ & $\theta$ & $M L^{2} T^{-2} \theta^{-1}$ \\
\hline
\end{tabular}

Following the dimensional method, we can calculate dimensionless numbers which are just two:

$$
\pi_{1}=\frac{\Delta \sigma l^{3}}{k \vartheta}
$$




$$
\pi_{2}=\frac{a t}{l^{2}}
$$

According to the Buckingham Theorem, one number is functionally related to another one, as follows:

$$
\pi_{1}=g\left(\pi_{2}\right)
$$

Inserting (2) and (3) into (4) and expressing $\Delta \sigma$, we can obtain:

$$
\Delta \sigma=\frac{k \vartheta}{l^{3}} g\left(\frac{a t}{l^{2}}\right)
$$

So far, the current formula (5) does not reflect the quantity relationship between all the values, therefore the research of interrelationship between $\Delta \sigma$ and $a$ has been carried out.

Fitting the obtained data by means of linear dependence (least-square fit method) $\Delta \sigma=$ $\gamma a$, where $\gamma$ - proportionality factor, we can calculate this coefficient:

$$
\gamma=8,8 \cdot 10^{9} \frac{\mathrm{H} \cdot \mathrm{C}}{\mathrm{M}^{4}}
$$

Taking into the account the direct proportional relationship between strength loss and temperature diffusivity coefficient of the material, the formula (5) would look like this:

$$
\Delta \sigma=\beta \cdot \frac{k \vartheta t}{l^{5}} \cdot a
$$

where: $\beta$-dimensionless proportionality factor.

It could be calculated under the following experimental conditions:

$\vartheta=873 \mathrm{~K}\left(600^{\circ} \mathrm{C}\right)$,

$t=60 \mathrm{~min}=3600 \mathrm{sec}$,

$l=10 \mathrm{~cm}=10^{-1} \mathrm{~m}$,

$k=1,38 \cdot 10^{-23} \frac{J}{K}$

$$
\gamma=8,8 \cdot 10^{9} \frac{\mathrm{H} \cdot \mathrm{c}}{\mathrm{M}^{4}}=\beta \cdot \frac{k \vartheta t}{l^{5}}=\beta \cdot \frac{1,38 \cdot 10^{-23} \cdot 873 \cdot 3600}{10^{-5}}=\beta \cdot 4,3 \cdot 10^{-12}
$$

Based on the above

$$
\beta=2,0 \cdot 10^{21}
$$

In the final variant, the formula (6) would look like this:

$$
\Delta \sigma=\frac{\vartheta a}{l^{5}} \cdot t
$$

Following on from the formula (7), it can be said that strength loss is proportional to temperature, process time and in inverse proportion to the dimension of element to the fifth power. That's why in real conditions, taking into account dimensions (thickness) of floor slabs and walls materials, according to the formula (7) it's possible to calculate the required time of fire provided strength of materials would reach certain percentage.

Then, we test the obtained analytical model on the specimen of cement compositions.

On the grounds of (7), we can calculate the value $t$ which corresponds to ultimate limit state point of cement composition by strength loss.

$$
t=\frac{\Delta \sigma \cdot l^{5}}{\vartheta \cdot a}
$$

$t$ - ultimate limit state point by strength loss, sec.

$\Delta \sigma$ - acceptable strength limit (strength after heating), $\mathrm{Pa}$

$l$ - width of structural element, $\mathrm{m}$

$\vartheta$ - temperature of heating structure, K

$a$ - temperature diffusivity, $\mathrm{m}^{2} / \mathrm{sec}$ 
For valuation of the ultimate limit state point of building structures exposed to temperatures $800^{\circ} \mathrm{C}$, we calculate the time required for the beginning of structural element failure under the specified characteristic load (estimated by laboratory testing, ultimate compressive strength, MPa). When fire resistance following the loss of bearing capacity had been evaluated by means of the proposed model, the ultimate limit state point is calculated by means of the standard method in compliance with Construction Rules and Regulations II-280 (GUIDE on Determination of Fire resistance Limits for Structures \& Flame propagation Limits over Structures and of Material Combustibility Groups).

The calculation of fire resistance limits following the strength loss was carried out for the specimen of cement compositions according to the developed model. The results are presented in the Table 2.

Table 2. Cement compositions used for calculation

\begin{tabular}{|c|c|c|c|c|c|c|c|c|c|}
\hline 乙 & $\begin{array}{l}\stackrel{8}{0} \\
\sum^{n} \\
\stackrel{0}{0} \\
\stackrel{0}{0}\end{array}$ & 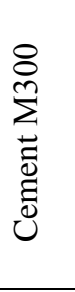 & 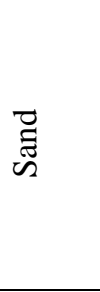 & 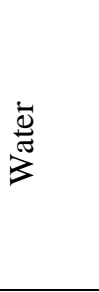 & 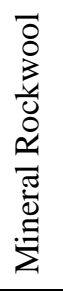 & 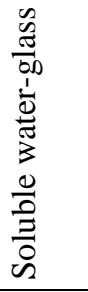 & $\begin{array}{l}\tilde{n} \\
\tilde{a} \\
00 \\
\tilde{0} \\
\tilde{0} \\
0 \\
0 \\
0\end{array}$ & 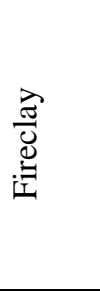 & 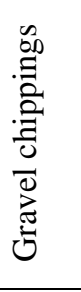 \\
\hline $1^{*}$ & 29 & - & 57.0 & 14 & - & - & - & - & - \\
\hline 3 & 29 & - & 56.8 & 14 & - & 0.2 & - & - & - \\
\hline 4 & 29 & - & 56.8 & 14 & - & - & 0.2 & - & - \\
\hline 7. & 19 & - & 15 & 10 & - & - & - & - & 56 \\
\hline 8 & - & 19 & 15 & 10 & - & - & - & - & 56 \\
\hline 9 & 18.56 & - & 53.63 & 24.75 & - & - & - & 3.06 & - \\
\hline
\end{tabular}

*Specimen 1 -sample

The specimen 1 was taken as a sample for calculation of fire-resistance time following the strength loss, then the ultimate limit state point was estimated in such structural elements like a cube with the dimensions 100x100x100mm and a standard floor slab, after that the similar evaluations for different compositions with the subsequent analysis of the obtained data is to be carried out.

Such input data as temperature diffusivity and acceptable strength limit (strength after heating) have been obtained by laboratory testing in compliance with [10, 11]. Heating temperature was risen up to $800^{\circ} \mathrm{C}$.

Table 3. Input data for implementation of analytical calculation following the ultimate limit state point estimate

\begin{tabular}{|l|c|c|c|c|c|}
\hline NN & $\begin{array}{c}\text { N of compo- } \\
\text { sition }\end{array}$ & $\begin{array}{c}\text { Acceptable } \\
\text { strength limit } \\
\text { strength after } \\
\text { heating), Pa }\end{array}$ & $\begin{array}{c}\text { Width of } \\
\text { structural } \\
\text { element, } \mathrm{m}\end{array}$ & $\begin{array}{c}\text { Temperature of } \\
\text { structure heat- } \\
\text { ing, K }\end{array}$ & $\begin{array}{c}\text { Temperature } \\
\text { diffusivity, } \\
\mathrm{m}^{2} / \mathrm{sec}\end{array}$ \\
\hline \multicolumn{6}{|c|}{ Structural element - cube } \\
\hline 1 & 1 & $23.6 \cdot 10^{3}$ & 0.1 & 800 & 0.000209 \\
\hline 3 & 2 & $23.6 \cdot 10^{3}$ & 0.1 & 800 & 0.000254 \\
\hline 4 & 3 & $16.8 \cdot 10^{3}$ & 0.1 & 800 & 0.000192 \\
\hline
\end{tabular}




\begin{tabular}{|l|l|l|l|l|l|}
\hline 5 & 5 & $5.28 \cdot 10^{3}$ & 0.1 & 800 & 0.000168 \\
\hline 6 & 6 & $35 \cdot 10^{3}$ & 0.1 & 800 & 0.000191 \\
\hline \multicolumn{7}{|c|}{ Structural element - floor slab } \\
\hline 1 & 1 & $52.4 \cdot 10^{3}$ & 0.22 & 800 & 0.000209 \\
\hline 2 & 2 & $26.7 \cdot 10^{3}$ & 0.22 & 800 & 0.000254 \\
\hline 3 & 3 & $16.8 \cdot 10^{3}$ & 0.22 & 800 & 0.000192 \\
\hline 4 & 4 & $7,31.6 \cdot 10^{3}$ & 0.22 & 800 & 0.000147 \\
\hline 5 & 5 & $5.28 \cdot 10^{3}$ & 0.22 & 800 & 0.000168 \\
\hline 6 & 6 & $35 \cdot 10^{3}$ & 0.22 & 800 & 0.000191 \\
\hline
\end{tabular}

Then we calculate the structural element (the cube dimensions 100x100x100 mm):

$$
t_{1}^{\text {cube }}=\frac{23.6 \cdot 10^{6} \cdot 0.1^{5}}{1073 \cdot 0.000209}=1052 \mathrm{sec}=17 \mathrm{~min}
$$

We've carried out the calculation of the structural element (the floor slab (FS) with the thickness of $22 \mathrm{~cm}$, concrete grade B40), in the calculation we've taken the half of the floor slab thickness as the effect of temperature is one-sided, upward):

$$
\begin{gathered}
t_{1}^{F S}=\frac{52.4 \cdot 10^{6} \cdot 0.11^{5}}{1073 \cdot 0.000209}=3763 \mathrm{sec}=62 \mathrm{~min} \\
t_{2}^{\text {cube }}=\frac{23.6 \cdot 10^{6} \cdot 0.1^{5}}{1073 \cdot 0.000254}=980 \mathrm{sec}=16 \mathrm{~min} \\
t_{2}^{F S}=\frac{26,7 \cdot 10^{6} \cdot 0.11^{5}}{1073 \cdot 0.000254}=1577 \mathrm{sec}=26 \mathrm{~min} \\
t_{3}^{\text {cube }}=\frac{16.8 \cdot 10^{6} \cdot 0.1^{5}}{1073 \cdot 0.000192}=814 \mathrm{sec}=14 \mathrm{~min} \\
t_{3}^{F S}=\frac{16.8 \cdot 10^{6} \cdot 0.11^{5}}{1073 \cdot 0.000192}=1313 \mathrm{sec}=23 \mathrm{~min} \\
t_{4}^{\text {cube }}=\frac{7.31 \cdot 10^{6} \cdot 0.1^{5}}{1073 \cdot 0.000147}=461 \mathrm{sec}=8 \mathrm{~min} \\
t_{4}^{F S}=\frac{7.31 \cdot 10^{6} \cdot 0.11^{5}}{1073 \cdot 0.000192}=746 \mathrm{sec}=12 \mathrm{~min} \\
t_{5}^{\text {cube }}=\frac{5.28 \cdot 10^{6} \cdot 0.1^{5}}{1073 \cdot 0.000168}=292 \mathrm{sec}=5 \mathrm{~min} \\
t_{5}^{F S}=\frac{5.28 \cdot 10^{6} \cdot 0.11^{5}}{1073 \cdot 0.000168}=471 \mathrm{sec}=8 \mathrm{~min} \\
t_{6}^{\text {cube }}=\frac{35 \cdot 10^{6} \cdot 0.1^{5}}{1073 \cdot 0.000191}=1941 \mathrm{sec}=32 \mathrm{~min} \\
t_{6}^{F S}=\frac{35 \cdot 10^{6} \cdot 0.11^{5}}{1073 \cdot 0.000191}=3127 \mathrm{sec}=52 \mathrm{~min}
\end{gathered}
$$




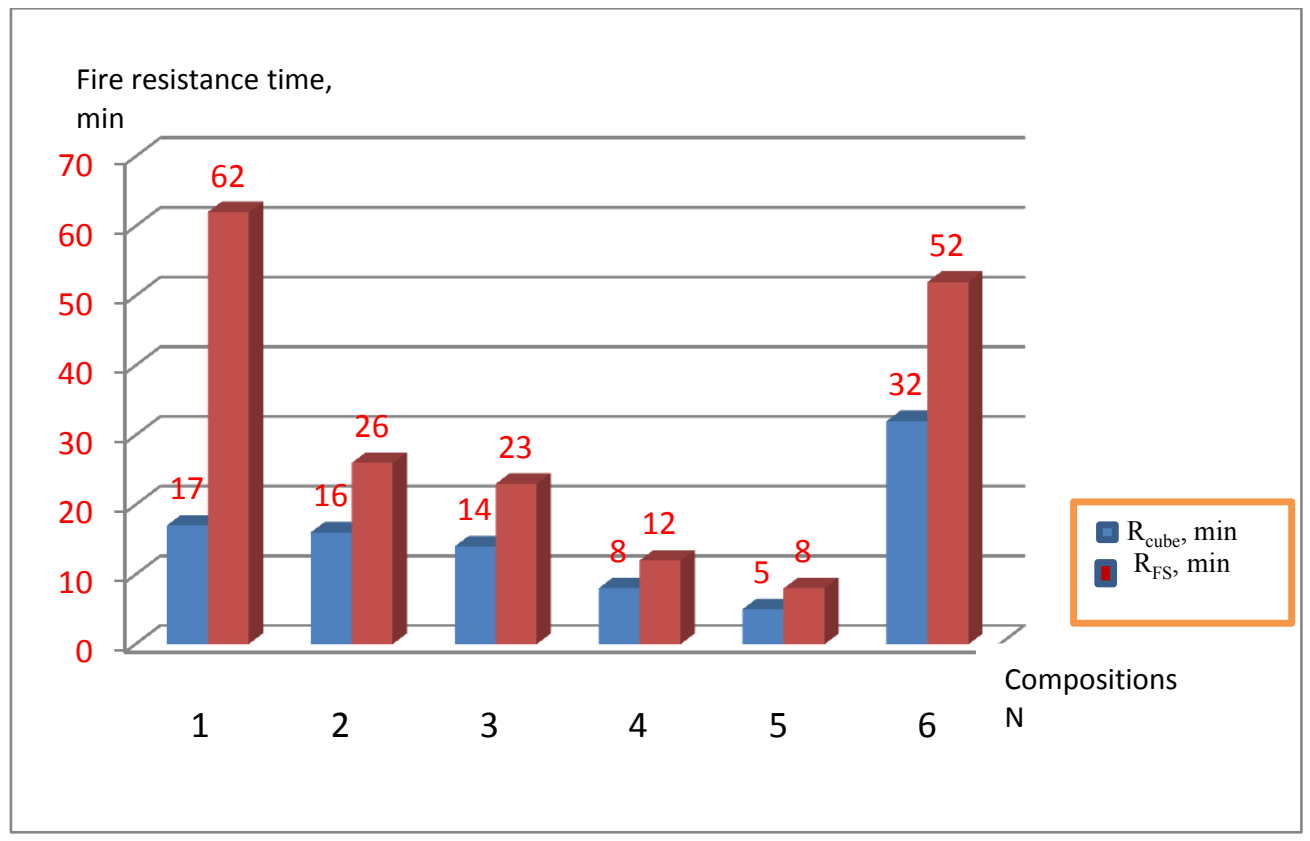

Fig.1. Comparative analysis of ultimate limit state point following the load-bearing capacity loss of cement compositions according to the results of application of the calculation model of fire resistance

\section{Conclusion}

Resulting from the implemented calculations, one can make a conclusion regarding the possibility of applying the proposed method to evaluation of fire resistance of newly developed materials which are lacking the reference data. That also proves the theory that strength loss of building structures on the base of cement compositions is proportional to heating temperature and time and is inversely proportional to the dimension of the element to the fifth power. That's why in the real conditions, taking into account the dimensions (thickness) of floor slabs and walls materials, the time of fire causing non-recoverable deflection of the researched material could be evaluated by means of this method.

\section{References}

1. National State Standard (GOST) 30247.0-94. Building Structures. Fire resistance Testing. The General Rules (Moscow, Publishing House of Standards, 1996)

2. N. Levashov, M. Akulova, O. Potemkina, Pozharvzrivobezopasnost, 24, E 10, 30-34 (2015)

3. A. Król Paweł. Bezpieczenstwo i technika pozarnicza, 35, doi 73-96. 10.12845/bitp.35.3.2014.7 (2014)

4. R. Fike, V. Kodur, J. of Fire Prot. Eng, 4, 229-259. doi: 10.1177/1042391509105597 (2009)

5. G. Peng, Evaluation of fire damage to high-performance concrete. Dis. Ph.D. Hong Kong Polytechnic Institute. Hong Kong (2000) 
6. O. Molchadskij, The Forecast of contribution of construction products to the propagation of fire while using the methods of thermal analysis. Dis. Ph.D. Moscow, 209 (2001)

7. S. Fedosov, N. Levashov, M. Akulova, O. Potemkina, J. Const. and Renov., 72, E 4, 119-128 (2017)

8. N. Levashov, M. Akulova, O. Potemkina, J. Fire and Emergency Sit., E 4, 75-78 (2015)

9. S. Fedosov, N. Levashov, M. Akulova, O. Potemkina, S. Zhivotyagina, J. Fire and Explosion Safety, 25, E 10, 14-21 (2016)

10. National State Standard (GOST) 7076-99. Buildings materials and structures. The method of defining temperature conductivity and thermal resistance at the standard thermal behaviour (Moscow, Publishing House of Standards, 1999)

11. National State Standard (GOST) 310.4-81. Cements of estimation of bending stress and ultimate compressive strength (Moscow, Publishing House of Standards, 1983) 